\title{
A formação crítica de alunos e professores de inglês: uma relação entre escrita, argumentação e letramento crítico
}

\author{
The critical education of English teachers and students: a \\ relationship between writing, argumentation and critical \\ literacy
}

\author{
Raphaela Priscylla Barros Campbell* \\ Sérgio Ifa**
}

\begin{abstract}
RESUMO: Como professores e pesquisadores, pretendemos promover a formação crítica dos alunos da nossa universidade por meio do ensino de línguas. Ao almejar essa formação, tentando não prejudicar o desenvolvimento das habilidades linguísticas, decidimos conduzir uma pesquisa-ação (BURNS, 2009) para compreender os processos de argumentação escrita e da formação crítica. Brydon (2010), Duboc (2012) e Jordão (2013) norteiam nosso estudo com relação ao letramento crítico, enquanto fundamentamo-nos principalmente em Liberali (2009) e Harmer (2007) para escrever sobre argumentação e escrita. Coletamos os dados por meio de anotações da professora observadora, dos textos escritos pelos alunos e dos planos e diários de aula. A interpretação de dados revelou que o processo de desenvolvimento da argumentação se fez mais relevante que uma possível adesão recorrente dela, contribuindo melhor para a formação crítica. Além disso, combinar docência com pesquisa resultou em reflexões que poderão ocasionar mudanças em nossas práticas docentes.
\end{abstract}

PALAVRAS-CHAVE: Letramento crítico. Argumentação. Process writing.

ABSTRACT: As teachers and researchers, we intend to promote our university's students' critical education through language teaching. Seeking this education while trying not to cause damage to the development of linguistic skills, we have decided to conduct an action research (BURNS, 2009) to understand the processes of written argumentation and critical education. Brydon (2010), Duboc (2012) and Jordão (2013) guide our study in terms of critical literacy, whereas we find support mainly in Liberali (2009) and Harmer (2007) to write about argumentation and writing. We have

\footnotetext{
* Graduada em Letras Inglês pela Universidade Federal de Alagoas. Mestranda em Estudos em Comunicação e Professora Assistente pela Universidade de Montana, Estados Unidos. E-mail: raphaelapbs@gmail.com.

** Doutor em Linguística Aplicada pelo LAEL/PUC-SP. Professor do PPGLL - linha Linguística Aplicada e da graduação da Faculdade de Letras na Universidade Federal de Alagoas. Líder do grupo de pesquisa Letramentos, Educação e Transculturalidade (LET-UFAL). Coordenador do Idiomas sem Fronteiras da UFAL (MEC/SeSU/CAPES). Coordenador do Projeto Casas de Cultura no Campus. E-mail: sergio.letras@gmail.com.
} 
collected data through the teaching assistant's notes, the texts written by students, lesson plans and journals. The data interpretation revealed that the argumentation development process has become more relevant than a possible agreement that could result from it, better contributing for critical education. Besides, combining teaching and research has resulted in observation that might cause changes in our teaching practices.

KEYWORDS: Critical literacy. Argumentation. Process writing.

\section{Introdução}

O Inglês sem Fronteiras (IsF) é um programa do governo federal brasileiro cujo objetivo principal é promover a internacionalização das universidades federais por meio do ensino-aprendizagem de línguas e outras ações, com o respaldo dos Núcleos de Línguas (NucLis). O NucLi da Universidade Federal de Alagoas (UFAL) visa a formação crítica de alunos e professores de inglês. Nosso grande desafio, como professores, tem sido o de promover a formação crítica e o desenvolvimento linguístico-discursivo dos alunos. Analisando o contexto e a necessidade deles, vimos a importância de desenvolver a escrita argumentativa, dado o fato de esse tipo de escrita ser o mais exigido para os alunos graduandos. O objetivo da pesquisa foi, portanto, compreender o processo de ensino-aprendizagem da argumentação escrita em língua inglesa por meio do letramento crítico (LC). A partir desse objetivo, selecionamos teorias relacionadas ao ensino de escrita (writing), argumentação e LC, fazendo uma ponte entre o que os teóricos dizem e o que encontramos na prática.

Discutimos tais teorias na próxima seção. Descrevemos, na sequência, os aspectos metodológicos da pesquisa, como o contexto, os participantes e os instrumentos de coleta de dados. A interpretação dos dados foi dividida em duas partes: na primeira, apresentamos as reflexões inerentes à experiência tida nas aulas; na segunda, as reflexões feitas após leitura dos textos escritos pelos alunos. Finalmente, fizemos algumas considerações sobre a pesquisa.

\section{Um pouco sobre o ideal}


Nesta seção, apresentamos nossa leitura de Harmer (2007) e Seow (2002) para descrever a abordagem denominada process writing, que foi a escolhida para desenvolver a escrita dos alunos do NucLi UFAL. Em seguida, discutimos concepções de LC e as relacionamos à formação de professores, fundamentando-nos no documento do Department of Education Tasmania (2004), Brydon (2010), Cervetti, Pardales e Damico (2001), Duboc (2012) e Jordão (2013).

A process writing ${ }^{1}$ é uma abordagem de ensino-aprendizagem de escrita que diverge a produção escrita do texto de uma para várias etapas, não se concentrando apenas em um produto final. A primeira delas é o planejamento (HARMER, 2007; SEOW, 2002), que envolve coletar ideias para o texto e pensar em maneiras de organizá-las para cumprir seu objetivo. Concordamos com Kroll (2001, p. 223) quando sugere dedicar mais tempo a esse período inicial da escrita, elevando o nível de confiança dos alunos e garantindo que eles tenham por onde começar. Já na segunda etapa, o rascunho, tópicos centrais são destrinchados, sem que haja necessariamente preocupação com aspectos formais do texto, como ortografia e pontuação. Revisão é a terceira etapa, na qual os alunos leem e avaliam o que escreveram e reescrevem o texto, se necessário, chegando à versão final. O processo de escrita é dinâmico, ou seja, a ordem das etapas pode ser diferente, além de existir a possibilidade de repeti-las. A process writing possibilita que a interação dos alunos entre eles e seus textos seja diversificada, além de facilitar o desenvolvimento progressivo da habilidade.

Uma característica fundamental nos textos que nossos alunos precisam escrever durante a graduação é a argumentação, um termo cuja definição é apresentada de diferentes maneiras por diferentes autores. A interpretação que Galinari (2014) faz dos diversos textos sobre retórica e argumentação revela que os autores demonstram uma superioridade moral desta em relação à primeira. $\mathrm{O}$ autor aponta que normalmente é feita uma associação entre

\footnotetext{
${ }^{1}$ Usamos process writing no gênero feminino por omitir a palavra abordagem. Usamos o termo em inglês para evitar confusão entre o processo de escrita e a escrita em processo.
} 
retórica e manipulação, enquanto a argumentação é elevada ao status de "exposição lógica, verídica e coerente das ideias". Ele defende que não há diferença entre argumentação e retórica, desde que haja procedimentos discursivos que objetivem alguma adesão. Discordamos do autor por encarar a argumentação como um conceito mais amplo, que não necessariamente busca a adesão. Liberali (2009) vê a argumentação como um meio, entendendo as atividades de discussão como ferramenta para localização do indivíduo na totalidade. Spinoza (1677 apud LIBERALI, 2009) elucida que todos nós, seres humanos, somos parte de um todo e nossas propriedades relativizam-se a este todo. A autora acima acrescenta que é na coletividade que compreendemos melhor as ideias do todo, e propõe que aplique o conceito de "Cadeia Criativa", que

implica esforços em parceria, em uma atividade, produzindo significados que serão, posteriormente, compartilhados com outros novos parceiros pelos sentidos (VYGOTSKY, 1934) que aqueles trazem para uma nova atividade. Portanto, novos significados são produzidos trazendo alguns aspectos criados na primeira atividade. Semelhantemente, alguns parceiros da segunda atividade, quando engajados em uma terceira atividade, seguem o mesmo caminho. Esta Cadeia Criativa pressupõe que características da totalidade emergem na produção de novos resultados criativos e de seus criadores (LIBERALI, 2009, p. 102, tradução nossa).

As discussões que promovemos nas salas de aula do IsF são inspiradas por esse conceito. Tentamos fazer com que os alunos realizassem trocas, facilitando a interação e a (re)construção de (novos) significados. Em outras palavras, pretendemos que os alunos compartilhem uns com os outros para rever suas posições. Com isso, esperamos que os alunos, no futuro, façam uso da argumentação para uma construção colaborativa de significados em detrimento da argumentação para persuasão/convencimento. Esperamos, como Liberali (2009, p. 109-110), desenvolver a argumentação para ser usada como "ferramenta para superar as perspectivas autoritárias e dogmáticas ambas do senso comum (sentido ou tema) e do conhecimento científico (significados objetivos cristalizados)" (tradução nossa). 
Na teoria da argumentação, encontramos três meios para desenvolver o processo argumentativo: logos, patos e ethos. O logos é um tipo de argumento centrado na forma com a qual a argumentação é construída. Um orador que o utiliza pretende fazer com que o interlocutor adira a um argumento pelo fato de esse fazer sentido, simplesmente. Já em relação aos outros dois, Reboul (2004, p. 48) resume: "o etos é o caráter que o orador deve assumir para inspirar confiança no auditório" e "o patos é o conjunto de emoções, paixões e sentimentos que o orador deve suscitar no auditório com seu discurso". Galinari (2014) apresenta uma perspectiva diferente para a temática e, fundamentado em Meyer (2007), o autor sugere que logos, patos e ethos sejam compreendidos não como três elementos distintos de uma teoria, mas como partes de um todo, uma vez que "o orador, o auditório e a linguagem são igualmente essenciais". Na prática de sala de aula, achamos interessante que os alunos saibam equilibrar o foco entre os três, a depender do que eles dispõem em relação a orador, auditório e linguagem. Caso considerem não ter vocabulário suficiente sobre determinado tópico, por exemplo, podem superar essa dificuldade focando as atenções no auditório, buscando atender as necessidades e/ou expectativas deste.

Mais a fundo, encaramos a argumentação como parte do processo de formação crítica. Letramento crítico é uma "perspectiva educacional" (JORDÃO, 2013 , p. 71) que tem como um dos objetivos a formação crítica dos alunoscidadãos, sendo vista como o caminho para uma sociedade mais justa, menos preconceituosa e mais tolerante. O LC implica a análise dos textos em seus contextos socioculturais específicos, mas também, como aponta o Departamento de Educação da Tasmânia, "a análise e crítica relações entre textos, língua, poder, grupos sociais e práticas sociais" (tradução nossa). Isso representa uma nova maneira de ler textos, o que pode acarretar mais participação dos alunos na construção de significados e possivelmente mais ação resultante dessa reconstrução, tornando-os "agentes de mudança social" (DEPARTMENT OF EDUCATION TASMANIA, 2004, tradução nossa). Stauffer (1969 apud CERVETTI; PARDALES; DAMICO, 2001) cita ao diferenciar o 
pensamento crítico do comum, pois este "é informal, casual e menos deliberativo" (tradução nossa).

Além dessa distinção (pensamento crítico VS. pensamento comum), consideramos relevante distinguir o LC de duas outras expressões: a pedagogia crítica e a leitura crítica. Duboc (2012, p. 84) resume:

O conceito de letramento crítico distingue-se do conceito de pedagogia crítica e de leitura crítica: do primeiro, porque nega a agenda revolucionária; e do segundo, porque se expande para além do trabalho objetivo e racional na decodificação dos sentidos textuais.

Se puder ser feita uma comparação entre leitura crítica e letramento crítico, aquela é mais passiva que este. A passividade consiste no conhecer ao se tentar compreender, enquanto o letramento consiste no conhecer ao reconstruir. A leitura crítica auxilia o aluno no entendimento das escolhas e significados apresentados pelos autores dos textos trabalhados em sala de aula, contudo, "não os levam necessariamente a desenvolver uma crítica social" (BRASIL, 2006, p. 116). Por que, então, se dar ao trabalho de desenvolver a leitura crítica? Para nós, esta abordagem funciona como um ponto de partida para o letramento crítico. Se os alunos tivessem que construir novos sentidos para os textos, sem antes ter feito uma leitura aprofundada, talvez não conseguissem ler nas entrelinhas. O Departamento de Educação da Tasmânia (DEPARTMENT OF EDUCATION TASMANIA, 2004) sugeriu uma sequência de procedimentos: "imersão, previsão, desconstrução, reconstrução e tomada de ação social" (tradução nossa). Isto é, após o aluno ser imerso no tema por meio do seu conhecimento de mundo e ter pressuposto o conteúdo do texto, a etapa de desconstrução, que está relacionada à leitura crítica, é essencial para a reconstrução dos significados.

Como o próprio nome sugere, a reconstrução envolve fazer algo novo a partir do que já existe. As Orientações Curriculares para o Ensino Médio (BRASIL, 2006), embora tratem de um contexto diferente do IsF, fornecem direções que ajudam os professores a buscar a formação crítica dos alunos. Sobre a justaposição do novo, o texto diz: 
Considerando, como vimos anteriormente, que o conhecimento é sempre social e culturalmente situado, os novos conhecimentos introduzidos em determinada prática sociocultural ou determinada comunidade de prática entrarão numa inter-relação com os conhecimentos já existentes. Nessa inter-relação entre o "novo" e o "velho", ambos se transformam, gerando conhecimentos "novos". Para que ele se torne um processo crítico e eficaz, é importante evitar, nessa inter-relação, a mera importação do novo, sem promover a devida interação com o velho, por meio da qual tanto o recém-importado quanto o previamente existente se transformarão, criando algo novo (BRASIL, 2006, p. 109).

Sendo assim, a construção de sentidos pode ser vista como uma tarefa conflituosa onde há pluralidade de ideologias, perspectivas e opiniões, como é o caso da sala de aula. Jordão (2013, p. 76) nos ensina que essa variedade é uma coisa boa, frutífera. Segundo a autora, aluno e professor constroem e negociam sentidos e podem perceber os resultados desses processos. Ademais, na sala de aula de língua inglesa, o conhecimento linguístico se amplia juntamente com o conhecimento de mundo, ou seja, os alunos têm duplo benefício. O Caderno de Orientações Didáticas para EJA² Língua Estrangeira Inglês (SÃO PAULO, 2010), assim como outros trabalhos na área conforme veremos adiante, sistematiza as considerações sobre diferentes perspectivas, apontando três denominações.

Nesse documento, as perspectivas são chamadas de pessoal, comunitária e global. Na perspectiva pessoal, o foco está no indivíduo. Alunos são convidados a olhar e falar sobre si mesmos, expondo seus sentimentos e suas interpretações do mundo. Essa perspectiva motiva inclusive o uso da língua por conta do apelo emocional que carrega. Já a perspectiva comunitária compreende o indivíduo como ser social, e seu objetivo é "sensibilizar o aluno para o fato de que semelhanças e diferenças de opiniões, atividades e valores têm origem nos contextos e grupos sociais aos quais cada um pertence (bairro, classe econômica, faixa etária, gênero masculino ou feminino, região geográfica, profissão)" (SÃO PAULO, 2010, p. 47). Abrangendo ainda mais

\footnotetext{
2 Educação de Jovens e Adultos.
} 
grupos, a perspectiva global prevê a verificação de semelhanças e diferenças entre culturas e nações. Defendemos a ideia de que mesmo que necessite das outras perspectivas para ser eficaz, o exame da perspectiva global é fundamental para a formação crítica do aluno. Para afirmar isso, baseamo-nos mais uma vez no Caderno de orientações didáticas para EJA Língua Estrangeira - Inglês (SÃO PAULO, 2010, p. 49): "o objetivo de focalizar na perspectiva global é mostrar que grupos grandes, como nações, são compostos de grupos diversos menores, procurando desfazer os estereótipos discriminatórios" (grifo dos autores). Por entender a formação crítica como uma ponte para uma sociedade mais igualitária, vemos essa compreensão do outro como uma necessidade.

Sobre as três perspectivas, Brydon (2010, p. 20) demonstra concordar com Street (2003) e Sylvester (1999) ao sustentar que os autores preferem combinações do local (comunitário) e global nas quais as perspectivas são interconstitutivas. Estamos de acordo com os autores por admitir que nenhuma das três é autossuficiente. Cabe a nós, professores, decidir como trabalhá-las em sala de aula, conforme são tomadas outras decisões relacionadas aos conteúdos (SÃO PAULO, 2010, p. 54).

No nosso contexto, vemos que o letramento crítico e a abordagem de diferentes perspectivas são essenciais para evitar que os alunos supervalorizem ideologias e culturas dos países anglófonos e falantes nativos de inglês. Os alunos precisam aprender a língua para expandir suas próprias visões e perspectivas e questionar tanto as suas quanto as dos outros, levando em consideração o ambiente global e o inglês como língua transnacional. Brydon (2010, p. 18) advoga a presença de duas visões sobre esse inglês no ensino de língua inglesa: a primeira reconhecendo sua utilidade para a comunicação entre nações nos diferentes contextos e a segunda questionando a hegemonia da língua, que traz embutidos os valores das nações dominantes. Tendo-se esses dois pontos de vista em evidência, a língua inglesa pode se tornar instrumento de mudança. 
O LC modifica também os professores, auxiliando na formação crítica entendida aqui como resultado das reflexões feitas nos planejamentos, nas aulas e após. Por ser mais que uma abordagem de ensino de língua, o letramento crítico inspira não apenas procedimentos, mas reconstruções de noções cristalizadas pelo ensino tradicional, cujo objeto de estudo principal era a estrutura da língua. No sentido contrário, o objetivo da educação no mundo globalizado de hoje deve ser a "consciência crítica" (CERVETTI; PARDALES; DAMICO, 2001). Inicialmente, esse propósito referia-se apenas aos alunos, mas como podemos desenvolver essa consciência nos alunos se nós mesmos não a tivermos? Acreditamos que essa seria uma tarefa que beira o impossível. Por esse motivo, defendemos que a formação crítica de professores seja um dos pilares do letramento crítico e vice-versa.

Entendemos a formação como interdisciplinar, característica que lhe é inerente. Duboc (2012, p. 74) sintetiza:

Formar um professor de inglês implica, dentre outros objetivos, tratar das formas de produção e interpretação de sentidos nos usos da linguagens, suas diferentes formas representacionais, os diferentes discursos nos quais nos inscrevemos e toda uma série de aspectos inerentes à disciplina. Tal como Barton e Hamilton (2000) advogam, compreender nossas práticas de letramento constitui um importante aspecto de nosso próprio processo de aprendizagem e, a meu ver, da compreensão de nossa própria formação identitária.

Concordamos com Gee (1986 apud BRASIL, 2006) quando ressalta a importância de compreender o professor de inglês como alguém que ensina mais que meramente uma língua. $O$ autor apresenta como uma possibilidade 0 autorreconhecimento dos professores como "pessoas que socializam os aprendizes numa visão de mundo que, dado seu poder [...] deve ser analisada criticamente" (GEE, 1986 apud BRASIL, 2006, p. 109). Brydon (2010, p. 18) completa esse raciocínio ao chamar atenção ao fato de porque a língua inglesa está incutida em "contextos históricos, culturais e sociais", o ensino desta não pode estar concentrado apenas na língua. $O$ inglês, talvez mais que outras línguas por estar tão difundido, carrega as ideologias e perspectivas dominantes, cabendo "a todas as classes negociarem seus sentidos e 
procedimentos interpretativos, construírem bases comuns para diálogo e estruturas sociais menos discriminatórias e preconceituosas" (JORDÃO, 2013, p. 80, grifo da autora).

Essa negociação recebe orientações de Cope e Kalantzis (2000 apud DUBOC, 2012, p. 81). Apesar de os primeiros autores referirem-se aos multiletramentos, percebemos que a "prática transformadora" também pode servir como guia para o trabalho com letramento crítico. Eles sugerem que se recriem os sentidos na diversidade do mundo globalizado, o que pode fazer com que os alunos se desarticulem parcialmente das suas concepções originais. Sendo assim, "ao enfocar a recriação dos textos disponíveis, a prática transformadora fundamenta-se no reconhecimento da heterogeneidade e da subjetividade nos processos de significação" (DUBOC, 2012, p. 81). Como professores, acreditamos que é por meio dessa mudança nas práticas de sala de aula que provocamos a mudança que queremos fora dela.

\section{Sobre metodologia}

A proposta de fazer essa mudança nos incentivou a escolher a pesquisaação como orientação metodológica, dada a dinamicidade que ela permite e o fato de lidarmos com docência e pesquisa ao mesmo tempo, já que temos uma professora-pesquisadora avaliando a própria prática. Burns (2009, p. 290) revela que a pesquisa-ação faz uma ponte entre o "ideal" e o "real", o que remetemos à teoria e à prática, trazendo os conceitos discutidos na LA. A autora traz o modelo de Kemmis e McTaggart, de 1988, que resumimos em quatro verbos: planejar, agir, observar e refletir. O planejamento das ações se deu a partir da análise do contexto em que trabalharíamos, que descrevemos a seguir. 0 curso de nível avançado teve duração de 64 horas, distribuídas em duas aulas semanais de duas horas cada, e aconteceu entre os meses de fevereiro e junho de 2014. Das 32 aulas do curso, escolhemos o tema "Drogas" 
para este artigo, que foi desenvolvido em quatro aulas. A turma teve 11 alunos $^{3}$ participantes da pesquisa, com idades entre 18 e 26 anos. Também participaram da pesquisa a English Teaching Assistant (ETA) Michelle ${ }^{4}$, atuando como professora-observadora e a professora Raphaela, que atuou como docente e também desenvolveu este trabalho. Michelle contribuiu com comentários sobre a aula que observou, respondendo aos nossos questionamentos. Essas anotações constituíram um dos nossos instrumentos de coleta de dados. Além dessas, recolhemos também as anotações que os alunos fizeram durante as discussões e durante o planejamento da escrita e os textos escritos produzidos pelos alunos. Utilizamos como instrumentos também os planos de aula e os diários de aula. Interpretamos os dados avaliando nossa prática docente e os resultados dessa prática para o desenvolvimento dos alunos.

\section{Sobre as aulas}

Nosso alvo principal como professores e pesquisadores foi a formação crítica dos alunos e a aprendizagem da escrita argumentativa. Aqui expomos como trabalhamos. De maneira geral, preparamos nossas aulas com o intuito de promover o letramento crítico sem que isso significasse o total esquecimento de aspectos estruturais da língua alvo. Pensamos que as discussões que provocamos em sala de aula, guiadas por perguntas que incitam a criticidade, podem ajudar a fazer com que os alunos não produzam discursos vazios, alienados.

Nossos objetivos exigiram que acontecesse um empenho maior no planejamento das aulas, de maneira que houvesse uma melhor preparação para vivenciar a sala de aula. Scrivener (1994, p. 109) assinala que o professor "nunca poderá prever completamente como os alunos responderão a alguma

\footnotetext{
${ }^{3}$ Todos os nomes dos alunos são fictícios visando preservar a identidade dos participantes. Todos os participantes preencheram o TCLE (Termo de Consentimento Livre e Esclarecido).

${ }^{4} \mathrm{O}$ nome é fictício para preservar a identidade da professora.
} 
coisa - mas quanto mais preparado estiver, mais provável será que você será capaz de lidar com o que acontecer" (tradução nossa). A primeira ação tomada no momento de planejar as aulas foi delimitar os objetivos para cada tema, reproduzidos a seguir. Os objetivos das aulas auxiliam na seleção dos procedimentos e orientam a tomada de decisões no momento das aulas.

\section{Objetivos:}

Ao término da aula, os alunos terão:

- Lido criticamente dois textos orais sobre drogas que contêm duas posições distintas.

- Praticado tempos verbais no pretérito.

- Pensado criticamente sobre drogas na etapa de planejamento da redação.

- Planejado/escrito sobre a opinião deles em relação às drogas. (Plano de aula 1 , tradução nossa)

Os procedimentos foram pensados de forma a abranger as etapas de imersão, previsão, desconstrução, reconstrução e tomada de ação social, conforme citamos anteriormente com base no documento do Departamento de Educação da Tasmânia (DEPARTMENT OF EDUCATION TASMANIA, 2004) e nos objetivos acima. Fizemos atividades de imersão e previsão que atraíssem a atenção dos alunos para os temas propostos. Visando o desenvolvimento linguístico, baseamo-nos também em etapas descritas em Harmer (2007, p. 275) e Oxford (1990, p. 58). Para a imersão, elaboramos um jogo para engajar os alunos no tema, etapa que Harmer (2007, p. 275) chama de "lead-in". Depois os alunos responderam em pequenos grupos a seguinte pergunta: "Are drugs good for you?", ou "As drogas fazem bem?".

Enquanto as opiniões foram ouvidas, houve a impressão de que quando um componente do grupo iniciava o papo defendendo determinado ponto de vista, os demais buscavam argumentos que apoiassem aquela ideia. Para redirecioná-los, foram feitas perguntas que os levassem a considerar uma perspectiva divergente. A professora-pesquisadora escreveu sobre isso em seu diário de aula e Michelle, em seu relato: 
Primeiro, eles só mencionaram coisas ruins sobre drogas. Eles mencionaram coisas como roubo, problemas de saúde, etc. Quando notei isso, interrompi um pouco e pedi que considerassem os dois lados. Então eles começaram a só dizer coisas boas sobre drogas. Eu acho que eles têm dificuldade em considerar dois pontos de vista ao mesmo tempo. Ao invés de interrompê-los, acredito que eu poderia ter Ihes dado subtópicos para que discutissem os dois lados. (Raphaela, diário de aula 2, tradução nossa).

Os alunos tenderam a focar no aspecto saúde das drogas quando discutiram se drogas faziam bem. Eles falaram como depende se alguém realmente precisa da droga por razões médicas e se sim, é mais aceitável. Quando a professora fez a pergunta sobre o que sofre, os alunos tenderam a focar apenas em aspectos negativos das drogas. (Michelle, diário de aula 2, tradução nossa).

Percebemos a influência que os alunos sofreram no debate. A tentativa de desviar a atenção da perspectiva de um dos colegas acabou impondo a contrária, de certa forma. Se os alunos tivessem trocado de grupo e conversado com mais pessoas, a variedade de opiniões poderia ser mais facilmente notada e explorada. Por isso, no diário, aparece a alternativa de apresentar subtópicos para os alunos discutirem (como saúde, diversão etc.) ao invés de interrompêlos na discussão.

Já nos processos de interpretação e construção de textos que tentamos fazer em nossas aulas, sentimos a necessidade de lidar com questões mais amplas que a linguística desses textos por meio da leitura crítica. Buscar uma compreensão menos superficial dos discursos faz parte do direcionamento para a formação crítica. Spache (1964 apud CERVETTI; PARDALES; DAMICO, 2001) cita ao definir leitura crítica "como um conjunto de habilidades que se estende além da alfabetização funcional e dos altos níveis de compreensão e análise" (tradução nossa). A compreensão e a leitura crítica de textos orais permitem ainda que seja feita uma análise de aspectos como entonação, sotaque, volume e tom de voz. Na terceira aula, os alunos ouviram a fala de um rapaz que defende a legalização das drogas. $O$ argumento que ele utilizou, além de mencionar o uso medicinal das drogas, foi o fato de várias pessoas conhecidas por sua inteligência notável ou seus grandes feitos terem feito uso de drogas ilícitas, citando inclusive nomes famosos e quais drogas eles escolheram. Com o 
propósito de suscitar a leitura crítica, elaboramos perguntas que provocassem esse tipo de leitura:

- Qual/Quais é/são seu/s propósito/s?

- Qual é a ideia central?

- Qual é a posição dele?

- Que evidência/s o texto apresenta?

- Que evidência/s ele omite? (Plano de aula 3, tradução nossa)

Esperávamos que os alunos, a partir dessas perguntas, fizessem uma leitura mais aprofundada dos textos orais que trouxemos para a sala de aula. Supusemos, quando fizemos o plano de aula, que após investigar as intenções e, de certa forma, analisar o discurso do autor, realizando a leitura crítica (BRASIL, 2006, p. 116), os alunos refletiriam sobre as perspectivas apresentadas ao selecionar as informações que seriam colocadas no texto e isso facilitaria a percepção de significados como construtos sociais e a posterior reconstrução destes. No diário de aula, consta a resposta dos alunos que mais chamou atenção da Raphaela:

Eu achei que a pergunta sobre evidências omitidas é complicada. Sinto que se eles só conseguem reconhecer a evidência apresentada, ficam cegos. Meus alunos apareceram com boas respostas para essa pergunta. Eles falaram sobre as pessoas que não usaram drogas e, ainda assim, são muito inteligentes e as pessoas que sofrem muito por conta das drogas. (Raphaela, diário de aula 3, tradução nossa)

Ao serem questionados sobre evidências que 0 autor não menciona, 0 que para nós pode ser uma técnica de manipulação, os alunos notaram a ausência de dados sobre pessoas também muito inteligentes que não usam drogas e sobre pessoas que sofrem por causa das drogas. $O$ interessante aqui é o fato de os alunos recorrerem ao que haviam discutido na primeira aula, o que compreendemos como uma tentativa de negociação de sentidos, processo que Jordão (2013, p. 76) sugere estar presente no âmbito escolar. Naquela aula, apesar de terem sido guiados, os alunos consideraram aspectos positivos e negativos das drogas, o que facilitou a realização da leitura crítica. 
As atividades relacionadas ao conhecimento de mundo e ao listening mencionadas anteriormente fizeram parte do processo de escrita, sendo parte da etapa de planejamento. Além destas, fizemos uma atividade de planejamento mais direta, cujo objetivo foi reconstruir significados ao selecionar ideias para escrever um texto. Priorizamos essa maneira de passar pela reconstrução porque já havíamos experimentado com reconstrução por meio de discussões, o que muitas vezes causou mal-estar entre os alunos nos temas mais polêmicos, além de contribuir para o silêncio dos mais tímidos. O lado negativo de não haver discussão é o fato de nem sempre podermos acompanhar o processo de reconstrução de significados. Na quarta aula, pedimos aos alunos que utilizassem as anotações feitas na primeira aula e durante a leitura crítica para responder a pergunta: "Should drugs be legalized in Maceio?", ou "As drogas devem ser legalizadas em Maceió?". Eles tiveram que fazer novas anotações a partir daquelas, porém, escolhendo três ideias principais que sustentassem suas posições em relação ao tema.

Após esse planejamento, no qual os alunos compartilharam suas anotações, não houve mais tempo para que os alunos fizessem os rascunhos em sala de aula. $O$ contexto do IsF dificultou a realização da process writing com as etapas descritas por Harmer (2007, p. 326), o que só foi percebido durante o desenvolvimento da pesquisa. A partir do meio do curso, os alunos passaram a reclamar sempre que tinham que escrever algum texto; escrever uma segunda versão se tornou para eles um tormento. Reforçamos, então, a necessidade de trabalhar a motivação dos alunos para a escrita e a execução da revisão (que nesta pesquisa foi feita pela professora) em tempo hábil. Muitos alunos não reconhecem a importância da escrita e não percebem como uma escrita apurada é valiosa para a academia. Os alunos optam por deixar o aprendizado da escrita em segundo plano. Para que os textos possam passar pela revisão mais rapidamente, novamente sugerimos que o foco esteja nos alunos. A revisão feita entre os colegas (SEOW, 2002, p. 318) pode ajudar a desenvolver a habilidade de leitura. Além disso, propomos que os alunos revisassem seus próprios textos de maneira guiada, questionando-se em 
relação aos diferentes aspectos dos textos. Tomamos as palavras-chave das seis orientações, para professores, que Kroll (2001, p. 226) elaborou e que podem refletir em questionamentos para os alunos avaliarem (editarem) seus próprios textos ou os dos colegas:

Quadro 1 - Orientações de Kroll (2001) para professores e perguntas para os alunos

\begin{tabular}{|ll|l|}
\hline \multicolumn{2}{|c|}{ Orientações de Kroll (2001) } & \multicolumn{1}{c|}{ Perguntas } \\
\hline 1. $\quad$ Contexto & $\begin{array}{l}\text { O texto cumpre os propósitos do autor e da tarefa no } \\
\text { contexto em que está inserido? }\end{array}$ \\
\hline 2. & Conteúdo & O conteúdo do texto está coerente com a proposta? \\
\hline 3. & Língua/Linguagem & $\begin{array}{l}\text { O texto está claro para o público ao qual o autor se } \\
\text { direciona? }\end{array}$ \\
\hline 4. & Tarefa & $\begin{array}{l}\text { O texto demonstra o conhecimento construído nas aulas } \\
\text { ou está aquém do esperado? }\end{array}$ \\
\hline 5. & Especificações retóricas & $\begin{array}{l}\text { A estrutura e o estilo do texto estão em consonância com } \\
\text { o perfil do leitor ao qual o autor espera atingir? }\end{array}$ \\
\hline 6. & Critérios de avaliação & O texto satisfaz os critérios de avaliação da tarefa? \\
\hline
\end{tabular}

Quando usamos a denominação tarefa, acima, referimo-nos não apenas à tarefa de sala de aula, mas à ação social que esperamos que o texto tome. Agora que colocamos essas perguntas em nosso trabalho, nos questionamos: por que não ter feito isso antes, quando ainda estávamos com a turma? A resposta encontrada é incômoda, porém, necessária. A professorapesquisadora, no final da pesquisa, passou a permitir que os alunos fossem 0 foco nas discussões em sala de aula, mas por outro lado, ainda atribuía a responsabilidade da avaliação e revisão a si, como se os alunos fossem dependentes. Sentia-se na obrigação de fazer o que indica Brown (1994, p. 325): "o que puder fazer como professor e guia e facilitador para ajudar seus alunos a revisar e refinar seu trabalho antes da submissão final ajudará a darIhes confiança em seu trabalho" (tradução nossa). Isso acarretou em trabalho excessivo para ela, que tentou assumir todos esses papéis e prejuízo para o aprendizado dos alunos. Precisava aprender a recuar para deixá-los avançar. Assim como a discussão entre indivíduos provenientes de diferentes contextos sociais não resulta em apenas uma conclusão, um texto sempre terá algo a ser modificado se lido por pessoas diferentes. 
Acreditamos na relevância desse processo da escrita por pensarmos na escrita como uma ação social. McLaughlin e DeVoogd (2004, p. 53) sugerem que a tomada de ação faz parte de uma postura crítica em relação à leitura. Os autores completam Cummins e Sayers (1995, p. 23) ao afirmarem que "boas intenções ou consciência de uma situação injusta não a transformará" (apud MCLAUGHLIN; DEVOOGD, 2004, p. 54). No momento da preparação de aula, imaginamos o rascunho sendo feito em sala de aula, como resultado da reflexão feita. Porém, o tempo disponível não era suficiente para a extensão dos textos pedidos e, por esse motivo, textos foram escritos fora da sala de aula. Harmer (2007, p. 326) antecipa a lentidão do processo como uma desvantagem da process writing. Sentimos a necessidade de um trabalho de conscientização sobre a importância de passar por esse longo processo.

\section{Sobre os textos dos alunos}

Vejamos, então, que resultados foram expressos por meio dos textos argumentativos dos alunos. Em pesquisas anteriores, observamos a intensa relação entre a argumentação e o processo de reconstrução dos textos. Tanto nas discussões com os colegas quanto na elaboração dos textos, os alunos desenvolvem seus argumentos na tentativa de estabelecer os significados que defendem. Nesses diálogos, são considerados diferentes pontos de vista existentes e são construídas novas percepções, por meio da interação com as perspectivas pessoais, comunitárias e globais.

Esperamos, a princípio, que os alunos defendessem suas posições por meio de seus textos de maneira espontânea. Porém, apesar de termos dito que os alunos tinham que convencer por meio dos textos escritos, eles não tinham uma noção clara do público para o qual estavam escrevendo pelo fato de a sala de aula ser um ambiente de produção artificial de língua ou assim o consideramos. Destacamos isso pelo fato de as conversas não poderem se desenrolar da mesma maneira que seriam fora deste ambiente, ou seja, a sala de aula apresenta restrições à comunicação justamente por ser um ambiente 
formal de aprendizado, de obrigações. Reforçamos nossas palavras citando Ducrot (1987, p. 176), ao afirmar que

para obedecer as regras da conversação, ele [o sujeito falante] escolhe responder ao tema proposto pelo interlocutor, mas a forma particular de sua resposta não resulta mais (ou é sobretudo dada como não resultando mais) da escolha.

Por outro lado, um grau de limitação é necessário para que haja civilidade e cortesia. Como profissionais da educação formal, desejávamos que os alunos pudessem dialogar e, no final da aula, chegar a uma conclusão unânime. Toulmin (2003, p. 20) avisa que nem sempre chegamos a esse final feliz, mas podemos tirar proveito das discussões de outras maneiras, como admitir novas possibilidades e/ou descartar certas perspectivas por meio da argumentação. Se antes gostaríamos que nossas aulas propiciassem um senso comum entre os alunos, com a experiência da pesquisa aprendemos que 0 processo, os significados que os alunos vão construindo e negociando uns com os outros são mais importantes que a conclusão.

Nesse caminho, os alunos vão se revelando e deixando transparecer suas escolhas. Alguns deles pareciam estar confusos, com dificuldades de se expressar, enquanto outros estavam bastante seguros e demonstraram isso na seleção das palavras e na redação do texto. A escolha da predominância de um dos caminhos (logos, patos e ethos) para a argumentação pareceu nos dizer muito sobre o autor e o conhecimento sobre o assunto. Comparemos partes dos textos de dois alunos ${ }^{5}$, César ${ }^{6}$ e Flávia.

In my opinion some drugs shouldn't be legalized in Brazil because it would make more people get sick and die and even kill other people intentionally or not. I agree that people are free to do whatever they wanted with theirselves (sic) but there is no reason to legalize something that will bring almost any benefit to the community?. (César)

\footnotetext{
${ }^{5}$ Os textos dos alunos foram mantidos em inglês para preservar a autenticidade do material coletado em sala de aula de língua inglesa.

${ }^{6}$ Todos os nomes são fictícios para preservar a identidade dos alunos.

${ }^{7} \mathrm{Na}$ minha opinião algumas drogas não deveriam ser legalizadas no Brasil porque faria mais pessoas ficarem doentes e morrerem e até matarem outras pessoas intencionalmente ou não. Eu concordo que as pessoas são livres para fazerem o que quiserem consigo mas não há razão
} 
Carl Hart, an American neuroscientist, states that the use of recreational drugs does not lead someone to addiction nor to the use of harder drugs. He believes that, just like alcohol, it is the user's responsibility to balance the dose he takes and deal with the effects. "You can drink socially or get wasted, it's up to you" says the neuroscientist.8 (Flávia)

O texto de César, por exemplo, revela que ele confia nas suas experiências para justificar sua opinião e as transforma em argumentos. Já Flávia, além de expor sua opinião, cita a explanação de um neurocientista que trata do uso de drogas. Em ambos os casos, entretanto, notamos que ethos foi um meio de persuasão utilizado para orientar o leitor. Por outro lado, vocábulos de conotação negativa como sick, violent, problem, accidents, overdoses, addiction, unemployment e crime, encontrados em outras partes dos textos, demonstram a tentativa de sensibilizar o leitor, característica da argumentação via patos. Por último, conseguimos enxergar logos através de modalizadores como In my opinion e operadores argumentativos como even e but. Ficou claro que não está evidente a predominância total de nenhum dos caminhos, ou seja, conforme Galinari (2014, p. 17) defende, os três meios de persuasão não devem estar dissociados.

Ducrot (1987, p. 166) considera que o texto "é na verdade, habitualmente, um discurso que se supõe ser objeto de uma única escolha, e cujo fim, por exemplo, já é previsto pelo autor no momento em que redige $o$ começo", mas nem sempre os alunos determinam seus objetivos antes de escrever o texto. Acreditamos que há um conflito interno em sala de aula que passa despercebido por nós, professores. Os alunos, durante a vida, são apresentados a diversas ideologias e perspectivas e, quando precisam tomar uma decisão para escrever um texto, por exemplo, trazem-nas à tona. Ao nosso

para legalizar algo que não trará quase nenhum benefício para a comunidade (César, tradução nossa).

${ }^{8}$ Carl Hart, um neurocientista americano, declara que o uso de drogas recreacionais não conduz ao vício nem ao uso de drogas mais pesadas. Ele acredita que, assim como o álcool, é responsabilidade do usuário equilibrar a dose que toma e lidar com os efeitos. "Você pode beber socialmente ou ficar chapado, depende de você", diz o neurocientista (Flávia, tradução nossa). 
ver, as discussões em grupo auxiliaram os alunos a tomar posições de maneira mais confiante.

Notamos que, semelhante ao que observamos ao fazer a leitura dos diários, os alunos tinham sido induzidos a dar certas respostas em seus textos. Percebemos um comportamento que necessita ser modificado. Quando foram feitas algumas das perguntas para trazer o conhecimento de mundo dos alunos, a professora-pesquisadora ficava calada, esperava respostas e fazia novas perguntas até que a resposta que gostaria de ouvir aparecesse. É preferível que as discussões sejam feitas em pequenos grupos, com o professor monitorando-os atentamente. Podemos ver a vantagem nesse tipo de interação onde os alunos argumentam entre si, posto que

o objetivo da argumentação é a construção de uma nova ideia dialetal como resultado de uma construção de conhecimento por todos aqueles envolvidos. Argumentação, neste caso, está relacionada não ao debate do que é verdadeiro ou mais lógico, mas à chance de criar novas possibilidades de compreender realidades (LIBERALI, 2009, p. 111, tradução nossa).

O intuito era que após discutir entre si e avaliar os textos orais, os alunos fariam uso da cadeia criativa para escrever seus textos, sendo que, considerando as diferentes posições e opiniões ao selecionar argumentos para seus textos, desenvolvendo assim sua formação crítica. Pedimos que eles escolhessem, dentre o que foi discutido e ouvido, três ideias principais que eles gostariam de incluir para defender suas posições. Esse exercício não foi válido no sentido de que não ajudou os alunos a compreender as falas como frutos das relações sociais, mas cremos que as anotações têm sua relevância no sentido de ajudá-los a escrever seus textos na língua alvo.

A aluna Sílvia, por exemplo, utilizou-as de maneira peculiar. O que chamou nossa atenção foi o fato de ela ter feito apenas anotações com evidências que levariam a determinada conclusão e escreveu defendendo uma posição oposta. Seguem suas anotações da primeira aula e um trecho de seu texto. 
- It depends.

- Deppression

- Drug addiction

- Brain cells

- Liver failure ${ }^{9}$ (Sílvia, em suas anotações)

When drugs are mentioned in a conversation, usually people tend to have strong opinions about it, and to think that they only bring bad things with them. And when the drug legalization is the subject, it gets even more hard to people actually believe that it can benefit us in some way. (...) The drug legalization would help the government to decrease the spending with things like the penitentiary system and hospital. But Just the legalization is the answer to this problem, but also regulations for all this good things happen. ${ }^{10}$ (Sílvia)

O que pudemos perceber ao comparar as anotações de Sílvia com o seu texto foi a mudança de perspectiva. Mesmo tendo anotado apenas aspectos negativos das drogas na primeira aula, ao fim das discussões e das atividades de listening, ela decidiu escrever a favor da legalização das drogas. Avaliamos isso como característica do letramento crítico, que a fez tomar partido de uma posição que não defendia antes após considerar outras possibilidades. Entendemos que questionar as ideologias dominantes ou não e suas origens é importante, porém, compreendê-las não é suficiente. Como mencionado, concebemos a ideia de admitir a escrita como uma forma de agir, mesmo sabendo que os textos não sairiam do ambiente da sala de aula. Sentimos falta, porém, de uma coerência entre as etapas de compreensão e de ação na nossa pesquisa. Priorizamos as discussões e não conseguimos acompanhar os processos de escrita, os quais merecem atenção maior. Se o objetivo do letramento crítico é a promoção de uma sociedade mais justa e igualitária (DEPARTMENT OF EDUCATION TASMANIA, 2004), a ação se faz necessária tanto quanto a compreensão.

\footnotetext{
9 - Depende. - Depressão - Vício em drogas - Células do cérebro - Falha do fígado (Sílvia, em suas anotações, tradução nossa)

10 Quando drogas são mencionadas em uma conversa, normalmente as pessoas tendem a ter opiniões fortes sobre isso, e a pensar que drogas só trazem coisas ruins. E quando legalização das drogas é o assunto, fica ainda mais difícil as pessoas realmente acreditarem que isso pode nos beneficiar de alguma maneira. [...] A legalização das drogas ajudaria o governo a diminuir os gastos com coisas como o sistema penitenciário e hospital. Mas só a legalização [não] é a resposta a esse problema, mas também regulacões para todas essas coisas boas acontecerem. (Sílvia, tradução nossa).
} 


\section{Algumas considerações}

Primeiramente, percebemos alguns questionamentos e direcionamentos para futuras pesquisas. Consolidamos na pesquisa necessidades que já tínhamos sentido, mas que não pusemos em prática por falta de dados que as apontassem para nós. Neste ponto, vamos de encontro a Duboc (2012, p. 84), apesar de tê-la utilizado na diferenciação entre letramento crítico e pedagogia crítica. Não cabe a nós afirmar que o letramento crítico "nega a agenda revolucionária", se o próprio LC faz parte de uma revolução no sistema educacional, pois rompe com pressupostos metodológicos usados há anos.

Nossa metodologia pode, inclusive, ser pauta de um diálogo interrogativo. A posição da professora-pesquisadora avaliando sua própria prática e usando termos relacionados à mudança e à transformação pode levar outros pesquisadores a indagar a imparcialidade da pesquisa. Lembramo-nos então da ressalva de Rajagopalan (2003, p. 111):

O que deve ficar claro é que a posição assumida por Searle e outros intelectuais que defendem uma pedagogia despolitizada é que a crença na neutralidade do educador é ela mesma uma atitude política - a de não perturbar a ordem das coisas que se encontra instalada, ainda que nela possam estar abrigadas severas injustiças e arbitrariedades gritantes.

Ora, se não podemos escapar de uma pedagogia política, também decidimos não escapar de uma pesquisa parcial, se esta puder trazer contribuições para essa pedagogia. Parcialidade, para nós, significou revelar as impressões que tivemos sobre as experiências em sala de aula, refletindo sobre elas no nosso contexto educacional, mas com o embasamento teórico necessário. Pensamos estar contribuindo mais dessa maneira do que se tentássemos esconder por trás de uma linguagem que se pretende neutra e imparcial. Barbosa (2003, p. 38) complementa que "só ocorrerão mudanças qualitativas na prática na sala de aula quando os professores as 
compreenderem e aceitarem como suas". Precisamos, como professores, sentir na pele o que as teorias discutem e sugerem e, assim, na prática, interpretar essa relação e seus resultados.

\section{Referências}

BARBOSA, Raquel Lazzari Leite (Org.). Formação de educadores: desafios e perspectivas. São Paulo: Ed. UNESP, 2003.

BRASIL. Ministério da Educação. Secretaria de Educação Básica. Orientações Curriculares para o Ensino Médio: Linguagens, códigos e suas tecnologias. Brasília, 2006. Disponível em:<http://portal.mec.gov.br/seb/arquivos/pdf/ book_volume_01_internet.pdf >. Acesso em: 1 mar. 2015.

BROWN, Douglas H. Teaching by principles: an interactive approach to language pedagogy. New York: Prentice Hall, 1994.

BRYDON, Diana. Critical literacies for globalizing times. Critical Literacies: Theories and Practices. v. 4, n. 2, p. 16-28, 2010. Disponível em: $<$ http://criticalliteracy.freehostia.com/index.php?journal=criticalliteracy\&page= article\&op=viewFile\&path\%5B\%5D=65\&path\%5B\%5D=44>. Acesso em: 3 mar. 2015.

BURNS, Anne. Action research in second language teacher education. In: BURNS, Anne; RICHARDS, Jack C. (Ed.). The Cambridge guide to second language teacher education. New York: Cambridge University, 2009.

CERVETTI, Gina.; PARDALES, Michael J.; DAMICO, James S. A tale of differences: Comparing the traditions, perspectives, and educational goals of critical reading and critical literacy. Reading Online, v. 4 n. 9, 2001. Disponível em: <http://www.readingonline.org/articles/art_index.asp?HREF=/articles/ cervetti/index.html>. Acesso em: 28 fev. 2014.

DEPARTMENT OF EDUCATION TASMANIA. School Education Division. English Learning Area: Critical literacy. 2004. Disponível em:

$<$ https://resources.oncourse.iu.edu/access/content/user/mikuleck/Filemanager_ Public_Files/L501/Unit\%201\%20Definitions/What\%20is\%20Critical\%20Literacy \%20\%202010.doc>. Acesso em: 11 fev. 2014.

DUBOC, Ana Paula Martinez. Atitude curricular: letramentos críticos nas brechas da formação de professores de inglês. 2012. 258 f. Tese (Doutorado em Letras) - Faculdade de Filosofia, Letras e Ciências Humanas, Universidade de São Paulo, 2012.

DUCROT, Osvald. O dizer e o dito. Revisão técnica da tradução Eduardo Guimarães. Campinas, SP: Pontes, 1987. 
GALINARI, Melliandro Mendes. Logos, ethos e patos: "três lados" da mesma moeda. Alfa: revista de linguística, São José Rio Preto, v. 58 n. 2, jun./dez. 2014. Disponível em: <http://www.scielo.br/scielo.php?pid=S198157942014000200257\&script=sci_arttext>. Acesso em: 3 mar. 2015.

HARMER, Jeremy. The Practice of English Language Teaching. $4^{\text {th }}$ ed. Harlow: Pearson Longman, 2007.

JORDÃO, Clarissa Menezes. Abordagem comunicativa, pedagogia crítica e letramento crítico - farinhas do mesmo saco? In: HILSDORF ROCHA, Cláudia; FRANCO MACIEL, Ruberval. (Org.). Língua estrangeira e formação cidadã: por entre discursos e práticas. Campinas: Pontes Editores, 2013. p. 69-90. (Coleção Novas Perspectivas em Linguística Aplicada, v. 33).

KROLL, Barbara. Considerations for teaching an ESL/EFL course. In: LARSENFREEMAN, Diane; CELCE-MURCIA, Marianne. (Ed.). Teaching English as a second or foreign language. $3^{\text {rd }}$ Ed. Boston: Heinle \& Heinle, 2001. p. 219-232.

LIBERALI, Fernanda Coelho. Creative Chain in the Process of Becoming a Totality. Bakhtiniana, São Paulo, v. 1, n. 2, p. 100-124, 2009.

MCLAUGHLIN, Maureen; DEVOOGD, Glenn. Critical Literacy as Comprehension: Expanding reader response. Journal of Adolescent and Adult Literacy, v. 48, n. 1, p. 52-62, 2004. Disponível em: <http://www.jstor.org/stable/40012284>. Acesso em: 18 jul. 2010.

OXFORD, Rebecca L. Language Learning Strategies. What every teacher should know. Boston: Heinle \& Heinle, 1990.

RAJAGOPALAN, Kanavillil. Por uma linguística crítica: linguagem, identidade e a questão ética. São Paulo: Parábola Editorial, 2003. (Coleção Lingua[gem.]).

REBOUL, Olivier. Introdução à retórica. Tradução de Ivone Castilho Benedetti. São Paulo: Martins Fontes, 2004.

SÃO PAULO (SP). Secretaria Municipal de Educação. Caderno de orientações didáticas para EJA Língua Estrangeira - Inglês. etapas complementar e final. São Paulo: SME, DOT, 2010.

SCRIVENER, Jim. Learning Teaching. Oxford: Macmillan, 1994.

SEOW, Anthony. The writing process and process writing. In: RICHARDS, Jack C; RENANDYA, Willy A. (Ed.). Methodology in language teaching: an anthology of current practice. New York: Cambridge University Press, 2002. p. 315-320.

STREET, B. What's 'new' in new literacy studies? Critical approaches to literacy in theory and practice. Current Issues in Comparative Education, v. 5, n. 2, p. 77-91, 2003. 
SYLVESTER, C. Development Studies and Postcolonial Studies: Disparate tales of the "Third World." Third World Quarterly, v. 20, n. 4, p. 703-721, 1999. TOULMIN, Stephen. The uses of argument. 1958. Cambridge: Cambridge University, 2003. 